\title{
Anatomical Variation of Position and Location of the Fibula Nutrient Foramen in Adult Kenyans
}

\author{
K.W. Ongeti, BSc Anat. (Hons.), Fourth year medical student, University of Nairobi, \\ M.M. Obimbo, MBChB, Medical Officer Intern, Kikuyu Mission Hospital, \\ P.K. Bundi, Third year medical student, University of Nairobi and \\ J. Ogeng'o, BSc. Anat (Hons.), MBChB, Lecturer, Department of Human Anatomy, \\ University of Nairobi \\ Correspondence to: \\ Mr. K.W. Ongeti, Department of Human Anatomy, College of Health Sciences, \\ University of Nairobi, P.O. Box 30197, 00100, Nairobi, Kenya
}

\begin{abstract}
Background: The fibula though transmits insignificant force in walking, is an important bone for muscle attachment and significant source of bone grafts.
\end{abstract}

Objectives: To determine the position, location and number of the nutrient foramina of the fibula among Kenyans.

Design: Cross-sectional descriptive study.

Subjects: Two hundred right and left dry fibulas for male and female Kenyans were obtained.

Setting: Department of Human Anatomy, University of Nairobi and the Osteology Department, National Museums of Kenya, Nairobi.

Methods: The number and position of the nutrient foramina were determined. The distance of the nutrient foramen from the styloid process of the head and the length of the fibula were measured by a tape. The data obtained was analyzed by a computer package, SPSS 11.5.0. The means of each value was compared between right, left and the gender groups.

Results: Five point five percent of fibula did not have any nutrient foramen. Most (53.4\%) of the nutrient foramina were located posteriorly. The average length of the fibula was $365 \pm 30 \mathrm{~mm}$ long while the nutrient foramen was located $153 \pm 24 \mathrm{~mm}$ from the tip of the styloid process of the head of the fibula; it was $3 \mathrm{~cm}$ proximal to the mid length of the fibula.

Conclusions: Fibula of $28.6 \mathrm{~cm}-\mathbf{4 1 . 2} \mathrm{cm}$ is available for grafting among Kenyans. The metric estimation of the position of the nutrient foramen of the fibula could assist in harvesting vascularised graft of the bone.

\section{INTRODUCTION}

The fibula is used as a vascularised graft for conditions such as stabilization of lost mandible, spine and even the tibia (1). Free vascularised fibula grafts offer a reliable method of reconstruction after excision of bone tumours and other massive bony defects (2). It is believed that meticulous preoperative planning, including choosing which vessels to select in the recipient and the type of fixation devices to use, and care in the introduction of the vascularised fibula, can improve the results and prevent complications $(3,4)$.
Potential complications of fibular graft harvesting include neurovascular injury, compartment syndrome, extensor hallucis longus weakness, and ankle instability. The neurovascular structures at risk for injury during fibular bone-graft harvesting include the peroneal nerves and their muscular branches in the proximal third of the fibular shaft and the peroneal vessels in the middle third (5). In spite of all these information, there is no clear data on the position of the nutrient foramen in the fibula. Among Kenyans, there is limited published information on the nutrient foramen of the fibula. 


\section{MATERIALS AND METHODS}

Two hundred fibulas were collected from the bone collection of the Department of Human Anatomy University of Nairobi, and the Osteology Department of the National Museums of Kenya, Nairobi. Full bone length adult fibulas were included in this study. Broken, unlabelled bones were excluded from this study. We reviewed 200 adult fibulas and determined the presence, number and position of the nutrient foramina using vernier calipers (precision 0.01). We measured the length of the fibula and the location of the nutrient foramen from the tip of the head using a tape. The collected data was recorded on data sheets. The collected data was coded and analyzed using the statistical program SPSS. The Students T-test will used to determine the significance of the means, Levenes test for the equality of variances while the Pearson's test will be used for correlation of symmetry. Tables, charts and scatter graphs will be used to illustrate the findings.

\section{RESULTS}

Population of study: Two hundred fibulas from 50 males and 50 females were used in this study. The mean length of the fibula was $365 \pm 30 \mathrm{~mm}$. The median length was $371 \mathrm{~mm}$ with a range of $286-412 \mathrm{~mm}$. The nutrient foramen was averagely $153 \pm 24 \mathrm{~mm}$ from the tip of the styloid process of the head of the fibula (Table 1).

Eleven fibulas (5.5\%) didn't have nutrient foramina. Nineteen fibulas (10.1\%) of the fibula had two nutrient foramina, the rest were single. All the multiple nutrient foramina were found in the females. The nutrient foramina were either anterior (9.5\%), medial (13.8\%), lateral $(13.8 \%)$ or posterior (53.8\%). The foramen of the nutrient foramen was larger in the males than in the females.

All measurements are in millimeters.

Table 1

The length and location of the fibula's nutrient foramen from the tip of the head

\begin{tabular}{lcc}
\hline Gender & $\begin{array}{c}\text { Length of the fibula } \\
\text { Male }\end{array}$ & $\begin{array}{c}\text { Distance from } \\
\text { the head }\end{array}$ \\
\hline Female & $358.7 \pm 11.93$ & $157.2 \pm 24.87$ \\
\hline
\end{tabular}

Compared to the average length of the fibula, the nutrient foramen was,

$$
\frac{365}{153}=2.38
$$

The half the length of the fibula is $182.5 \mathrm{~mm}$. The location of the nutrient foramen is;

$$
182.5-153=29.5 \mathrm{~mm}
$$

The Nutrient foramen therefore $2.95 \mathrm{~cm}=$ Approx $3 \mathrm{~cm}$, proximal to the midpoint of the fibula.

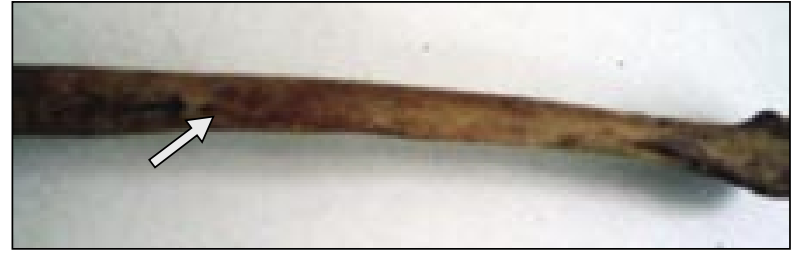

\section{DISCUSSION}

The average length of the fibula is $36 \mathrm{~cm}$. The fibula is significantly longer in the males than in the females. Kenyan fibula is longer compared to Mongolians whose fibula is $15 \mathrm{~cm}-20 \mathrm{~cm}$ long (1).

In the present study, we found the location of the nutrient foramen in the middle third of the fibula, $3 \mathrm{~cm}$ proximal to the mid length of the fibula. This position is similar to the described position among the Koreans, just proximal to the midpoint among Koreans (1). The commoner position of the nutrient foramen, posterior should always be noted to avoid injury to the nutrient foramen. Other positions of the nutrient foramen should be however anticipated.

Adequate dissection around the position and the location of the nutrient foramen will minimize the length of the incision in harvesting the fibula vascularised graft. This will minimize the complication of the procedure such as compartment syndrome (5).

In conclusion, the location of the nutrient foramen is important if a free vascularised fibular graft is to include endosteal as well as periosteal blood supply. In Kenyans $28.6 \mathrm{~cm}-41.2 \mathrm{~cm}$ of the fibula is available for grafting among Kenyans. The metric estimation of the position of the nutrient foramen of the fibula could assist in harvesting vascularised graft of the bone. 


\section{Limitations of the study}

1. This was a dry bone study and does not directly correlate with living samples.

2. There might have been a difference in the anatomy of the samples from the museum that have been stored for 50 years.

\section{REFERENCES}

1. Choi S.W., Kim H.J., Koh K.S., Chung I.H. and Cha I.H. Topographical anatomy of the fibula and peroneal artery in Koreans. Int. J. Oral Maxillofac. Surg. 2001; 4: 329-332.

2. Pollock R., Stalley P., Lee K. and Pennington D. Free vascularised fibula grafts in limb-salvage surgery. J. Reconstr. Microsurg. 2005; 2: 79-84.

3. Minami A., Kasashima T., Iwasaki N., Kato H. and Kaneda K. Vascularised fibular grafts: An experience of 102 patients. J. Bone Joint Surg. 2000.

4. Malizos A.N., Zalavras C.G., Soucacos P.N., Beris A.E., and Urbaniak J.R. Free vascularized fibular grafts for reconstruction of skeletal defects. J. Amer. Acad. Orthop. Surg. 2004; 12: 360-369.

5. Ebraheim N.A., Elgafy H. and Xu R. Bone-graft harvesting from iliac and fibular donor sites: Techniques and complications. J. Amer. Acad. Orthop. Surg. 2001; 9: 210218. 